\title{
Effects of Intravenous Laser Irradiation of Blood on Pain, Function and Depression of Fibromyalgia Patients
}

Pin Yi Wu ${ }^{1}$, I Wen Penn ${ }^{2}$, Pei Hsin Lin ${ }^{3}$, Jia Chi Wang ${ }^{1}$, Eric Chuang ${ }^{4}$, Szu Hsien Wu ${ }^{1}$ and Tien Yow Chuang ${ }^{1^{*}}$

${ }^{1}$ Department of Physical Medicine and Rehabilitation, National Yang-Ming University and Taipei Veterans General Hospital, Taipei, Taiwan

${ }^{2}$ Department of Physical Medicine and Rehabilitation, School of Medicine, Fu Jen Catholic University, New Taipei City, Taiwan

${ }^{3}$ Department of Rehabilitation and Technical Aid Center, Taipei Veterans General Hospital, Taiwan

${ }^{4}$ Department of Integrative Biology Alumnus, University of California, Berkeley, USA

"Corresponding author: Tien Yow Chuang, Professor, Department of Physical Medicine and Rehabilitation, National Yang-Ming University and Taipei Veterans General Hospital, Taipei, Taiwan, Tel: 886-2-28757296; Fax: 886-2-28757359; E-mail: tychuang@vghtpe.gov.tw

Rec date: Feb 14, 2018; Acc date: Feb 28, 2018; Pub date: March 8, 2018

Copyright: ( 2018 Pin YW, et al. this is an open-access article distributed under the terms of the Creative Commons Attribution License, which permits unrestricted use, distribution, and reproduction in any medium, provided the original author and source are credited.

\begin{abstract}
Objective: Fibromyalgia, labeled for an illness of wide spreading pain, fatigue, restless sleep, gastrointestinal disturbances, and mood disorders, is a complex and heterogeneous disease. Novel and improved treatments would allow healthcare professionals to improve the conditions of patients with fibromyalgia. For instance, photo biomodulation is a new treatment that minimizes heavy usage of drugs and side effects. This study investigated the clinical effects of intravenous laser irradiation of blood on pain, sleep, mood disorders, and quality of life in patients with fibromyalgia.
\end{abstract}

Methods: Fifteen patients diagnosed as having fibromyalgia based on the modified 2010 criteria of the American College of Rheumatology from an outpatient clinic were recruited. Before admission, all subjects were asked to submit visual analog scale (VAS), numbers of tender points, revised Fibromyalgia Impact Questionnaire (FIQR), revised Beck Depression Inventory (BDI) and Pittsburgh Sleep Quality Index (PSQI) according to their outcomes before/after drugs in a previous outpatient clinic. After admission, all participants received two courses of intravenous laser irradiation of blood, each course is composed of 10 intravenous laser irradiation of blood sessions, each session of the therapeutic duration lasted for 60 minutes. Two consecutive courses had a 7-day rest interval. The trial lasted for 4 weeks. Outcomes based on patient-reported symptoms of the aforementioned tests were evaluated on two separate occasions: baseline and within 24 hours after the last day of the protocol.

Results: The drugs resulted in significant reduction in pain intensity only. However, the before/after comparisons of intravenous laser irradiation of blood showed a significant improvement in VAS $(p=0.001)$, number of tender points $(p=0.002)$, FIQR $(p=0.001)$, BDI $(p=0.003)$ and PSQI $(p=0.01)$. We also noted significantly positive effects of ILIB compared with drugs in all tests.

Conclusion: Intravenous laser irradiation of blood had a better effect on pain severity, sleep, mood disorder, and quality of life in patients with fibromyalgia. No unfavorable events were recorded; thus, intravenous laser irradiation of blood appears to be an effective treatment for patients with fibromyalgia.

Keywords: Fibromyalgia; Quality of life; Intravenous laser irradiation of blood; Photo biomodulation; Chronic pain syndrome; Laser; Pain

\section{Introduction}

Fibromyalgia, which is characterized by wide spreading pain, fatigue, restless sleep, gastrointestinal disturbances, and mood disorders, is a complex and heterogeneous disease [1-3]. However, its pathogenesis remains to be clearly established. Numerous professionals assume the role of central nervous system (CNS) pain processing abnormalities in fibromyalgia, including central sensitization and inadequate pain inhibition [4,5], and tonic peripheral nociceptive input associated with augmented windup and/or central sensitization in responses to neurotransmitters, genetic features, psychosocial changes, and environmental stress [4-6].
Clinicians and researchers have observed minimal progress in the treatments available for fibromyalgia within the last 20 years. Recent developments in the understanding of fibromyalgia would allow the identification of both pharmacological and non-pharmacological ways targeting specific active mechanisms of the disease, thereby enabling an effective management of the patients' conditions [7]. Moreover, new and improved treatments would allow healthcare professionals to improve the conditions of patients with fibromyalgia, which is often overlooked and grossly underfunded. For instance, photo biomodulation is a new treatment that minimizes heavy usage of drugs and side effects $[8,9]$.

Low-level laser therapy (LLLT; topical laser) is one of the recent developments in the treatment of fibromyalgia [9-11]. LLLT can affect multiple signaling cascades and mechanisms associated with analgesia [12-14]. This therapeutic approach apparently increases $\beta$-endorphin levels, lymphatic flow, and blood supply. Moreover, researchers have 
indicated that specific doses of LLLT could reduce blood lactate, oxidative stress, and inflammatory biomarker levels, which in turn limits inflammation, fatigue, and induces muscle relaxation $[10,11,13,14]$.

However, because of the characteristic of pain and numerous tender points in patients with fibromyalgia, LLLT is typically performed for at least 20 minutes, moving from one tender point to another $[9,11,15]$. Intravenous laser irradiation of blood (ILIB), which is considered a safe therapeutic method, is more comfortable for patients. Another advantage of ILIB is that it requires less medical attention than the extracorporeal version $[12,16,17]$. In addition to the fundamental effects of LLLT, other integral influences of ILIB were also found, including positive effects on rheological properties of the blood, modulation of redox system in the mitochondria, and decreased oxidative stress makers [12,18]. Moreover, advantages of ILIB over LLLT can be expected as the former is more direct and less energyconsuming [16].

Currently, only two studies on "ILIB therapy patients with fibromyalgia are available": one is a non-randomized interventional study [17] and the other is a single descriptive study [12]. Although current treatment guidelines for fibromyalgia support the core concept of patient-tailored, multicomponent therapy $[19,20]$, in this study ILIB was used to investigate its therapeutic effect on pain, sleep condition, mood, and health-related quality of life (QOL).

\section{Materials and Methods}

\section{Participants}

All patients with fibromyalgia according to the modified 2010 criteria of the American College of Rheumatology(ACR) were recruited from an outpatient clinic in the Department of Rehabilitation and Physical Medicine, Taipei Veterans General Hospital, Taiwan $[21,22]$ Patients who had uncontrolled heart disease, who withdrew their participation because of personal reasons, and who were taking medications that caused sensitivity to light therapy (e.g. astemizole, estrogen, diclofenac, doxycycline) [23] were excluded.

Fifteen patients with fibromyalgia (all women) were included (mean age 53.77 years). Prior to hospital admission, all patients had been taking medications for at least 6 months and they were asked to provide pre-hospitalization data on pain intensity, depression and anxiety, sleep quality, and QOL. Most patients had tried one or more Food and Drug Administration-approved and/or off-label medications, such as pregabalin, duloxetine, and opioids. Most of the patients were advised to quit their medications if possible during admission; however, they were allowed to continue their current medications as they wish. This study was approved by our institution's human research committee and informed consent was obtained from all participants.

\section{Protocol}

All participants received two courses of ILIB; each course is composed of 10 ILIB sessions, and each therapeutic duration was 60 minutes. Two consecutive courses had a 7-day rest interval. During ILIB, each patient lay down in bed with supine position. A 24-gauge intravenous catheter was used for an elbow venous puncture (phlebotomy). The intravenous needle was subsequently replaced with a fiber-optic needle, which was inserted into the inner cannula of the intravenous catheter. The other side of the fiber optic needle was connected to a helium-neon laser illuminator (YJ-ILIB-5, Bio-ILIB Human Energy Ltd, Taiwan), which emits red-light laser in continuous wave mode with a wavelength of $632.8 \mathrm{~nm}$ and a power output of 2.5 $\mathrm{mW}$.

\section{Measurements}

\section{Pain assessment}

A visual analogue scale (VAS) was used to evaluate pain $(0=$ no pain and $10=$ as painful as imaginable) caused by fibromyalgia.

\section{Depression and anxiety}

The Revised Beck Depression Inventory (BDI) was employed for the assessment of depression. BDI is a widely used 21-item self-report inventory that measures the severity of depression in adolescents and adults [24].

\section{Sleep quality}

We used the Pittsburgh Sleep Quality Index (PSQI) to evaluate sleep conditions. It estimates sleep duration, sleep latency, and the frequency and severity of specific sleep-related problems during the past months. The index comprises 19 items which were grouped into 7 component scores, and weighted equally on a 4-point Likert scale, ranging from 0 (not during the past month) to 3 ( $\geq 3$ times a week). The component scores are summed to yield a global PSQI score (ranges from 0-21), with higher scores indicating worse quality of sleep. Reliability estimates showed internal consistency of 0.83 for the 7 component scores, and test-retest reliability of 0.85 for the PSQI global scores [25].

\section{Quality of life evaluation}

The QOL of the patients with fibromyalgia was assessed using the Revised Fibromyalgia Impact Questionnaire (FIQR) [26], which contains three domains similar to those of the Fibromyalgia Impact Questionnaire (FIQ; function, overall impact, and symptoms). However, it differs from the FIQ as function questions were modified and questions on memory, tenderness, balance and environmental sensitivity were included. All questions are graded from 0 to 10 . The FIQR is an updated version of the FIQ and has good psychometric properties, which could be easily scored and completed in 2 minutes.

The trial lasted for 4 weeks, and outcomes were evaluated on two separate occasions: baseline and within 24 hours after the last day of the protocol.

\section{Statistical Analyses}

Statistical analyses were performed with the SPSS 18.0 PC program. Results were expressed as mean \pm S.D. Wilcoxon rank-sum test (featuring non-parametric statistics) was used to compare the measurements of therapeutic outcomes pre/ post treatments and the gain differences between the effects of drug and ILIB, including pain, tender point, quality of life, sleep quality, and depression. $\mathrm{P}$ values $<0.05$ were considered statistically significant.

\section{Results}

Table 1 showed the demographic characteristics of all the participants. Comorbidity, medication history and medication at admission were also shown in Table 1 . All participants had received at least two types of drugs for fibromyalgia before admission. All the 
Citation: Pin YW, Penn IW, Lin PH, Wang JC, Chuang E, et al. (2018) Effects of Intravenous Laser Irradiation of Blood on Pain, Function and Depression of Fibromyalgia Patients. Gen Med (Los Angeles) 6: 310. doi:10.4172/2327-5146.1000310

participants were women with a mean age of 53.77 years (range: 31-64 years) and a mean body mass index of 24.30 (range: 17.9-32.65).

\begin{tabular}{|c|c|c|c|c|c|c|c|}
\hline Subject & Sex & Age (year) & BMI & $\begin{array}{l}\text { Fibromyalgia } \\
\text { duration (year) }\end{array}$ & Comorbidity & Medication History & $\begin{array}{l}\text { Medication at } \\
\text { admission }\end{array}$ \\
\hline \multirow{2}{*}{1} & \multirow{2}{*}{$\mathrm{F}$} & \multirow{2}{*}{31} & \multirow{2}{*}{17.9} & \multirow{2}{*}{3} & \multirow{2}{*}{ Osteoarthrosis } & Neurontin 7 months & Nil \\
\hline & & & & & & Anxiedin 9 months & \\
\hline \multirow{3}{*}{2} & \multirow{3}{*}{$\mathrm{F}$} & \multirow{3}{*}{56} & \multirow{3}{*}{21.5} & \multirow{3}{*}{7.5} & \multirow{3}{*}{ Poliomyelitis } & Dormicum 1 year & Flurbiprofen 5 years \\
\hline & & & & & & Lorazepam 1 year & \\
\hline & & & & & & Celecoxib 2 years & \\
\hline \multirow{7}{*}{3} & \multirow{7}{*}{$\mathrm{F}$} & \multirow{7}{*}{51} & \multirow{7}{*}{20.3} & \multirow{7}{*}{9} & \multirow{7}{*}{$\begin{array}{l}\text { Sicca syndrome; } \quad \mathrm{L} 4 / 5 \\
\text { Herniated intervertebral disc }\end{array}$} & Pregabalin 2 years & Estazolam 9 years \\
\hline & & & & & & Estazolam 9 years & Sertraline 8 years \\
\hline & & & & & & Sertraline 8 years & \\
\hline & & & & & & Xanax 3 months & \\
\hline & & & & & & Amitriptyline $4 \mathrm{v}$ & \\
\hline & & & & & & Ultracet 5 months & \\
\hline & & & & & & Celecoxib 5 months & \\
\hline \multirow{4}{*}{4} & \multirow{4}{*}{$\mathrm{F}$} & \multirow{4}{*}{51} & \multirow{4}{*}{22.9} & \multirow{4}{*}{5} & \multirow{4}{*}{$\begin{array}{l}\text { Depressive disorder; Breast } \\
\text { Fibroadenoma }\end{array}$} & Amitriptyline 1 year & Vytorin 4 years \\
\hline & & & & & & Pregabalin 6 months & Lipanthyl 4 years \\
\hline & & & & & & Alprazolam 6 months & \\
\hline & & & & & & Meitifen 5 months & \\
\hline \multirow{4}{*}{5} & \multirow{4}{*}{$\mathrm{F}$} & \multirow{4}{*}{59} & \multirow{4}{*}{29} & & & Remeron 4 years & Clonazepam 5 years \\
\hline & & & & 5 & Chronic $\quad$ migraine; & Zopiclone 5 years & Flunarizine 4 years \\
\hline & & & & & $\begin{array}{llr}\text { pituitary } & \text { fossa; } & \text { Major } \\
\text { depression } & 4 / 5\end{array}$ & Flunarizine 4 years & Remeron 4 years \\
\hline & & & & & Spondylolisthesis & Propranolol 4 years & Propranolol 4 years \\
\hline & & & & & & Clonazepam 5 years & Zopiclone 5 years \\
\hline & & & & & & Alprazolam 2 years & Salazine 6 years \\
\hline & & & & & & Salaxine 6 years & Eltroxin 6 years \\
\hline 6 & $\mathrm{~F}$ & 63 & 24.8 & 8 & Rheumatoid arthritis; & Zolpidem 8 years & Zolpidem 8 years \\
\hline & & & & & sleep apnea & Concor 1 year & Norvasc 3 years \\
\hline & & & & & & Clonazepam 1 year & \\
\hline & & & & & & Eltroxin 6 years & \\
\hline & & & & & & Pregabalin 2 years & Ultracet 3 years \\
\hline & & & & & & Ultracet 3 years & Celecoxib 1 year \\
\hline 7 & $\mathrm{~F}$ & 62 & 30.4 & 4 & syndrome; $\quad L 4 / 5 \quad$ herniated & Celecoxib 1 year & Crestor 3 years \\
\hline & & & & & & Crestor 3 years & Isosorbide \\
\hline & & & & & & Isosorbide mononitrate 3 years & mononitrate 3 years \\
\hline 8 & $\mathrm{~F}$ & 64 & 30.5 & 4 & $\begin{array}{l}\text { Sicca syndrome; } \quad \text { L4/5/S1 } \\
\text { spinal stenosis }\end{array}$ & Trazodone 7 months & Aspirin 1 year \\
\hline
\end{tabular}


Citation: Pin YW, Penn IW, Lin PH, Wang JC, Chuang E, et al. (2018) Effects of Intravenous Laser Irradiation of Blood on Pain, Function and Depression of Fibromyalgia Patients. Gen Med (Los Angeles) 6: 310. doi:10.4172/2327-5146.1000310

Page 4 of 8

\begin{tabular}{|c|c|c|c|c|c|c|c|}
\hline & & & & & \multirow{4}{*}{$\begin{array}{l}\text { mitral, aortic, and tricuspid } \\
\text { regurgitation; hypertension; } \\
\text { cataract }\end{array}$} & Clonazepam 2 years & Crestor 1 year \\
\hline & & & & & & Diclofenac 7 months & $\begin{array}{l}\text { Prednisolone } \\
\text { years }\end{array}$ \\
\hline & & & & & & Pregabalin 1 year & \\
\hline & & & & & & Prednisolone 2 years & \\
\hline \multirow[t]{2}{*}{9} & \multirow[t]{2}{*}{$\mathrm{F}$} & \multirow[t]{2}{*}{54} & \multirow[t]{2}{*}{22.3} & \multirow[t]{2}{*}{1} & \multirow{2}{*}{$\begin{array}{lr}\begin{array}{l}\text { Systemic } \\
\text { erythematosus; } \\
\text { spondylitis }\end{array} & \begin{array}{r}\text { lupus } \\
\text { ankylosing }\end{array}\end{array}$} & Pregabalin 4 months & $\begin{array}{l}\text { Proppranolol } \\
\text { months }\end{array}$ \\
\hline & & & & & & Proppranolol 6 months & \\
\hline \multirow{7}{*}{10} & \multirow{7}{*}{$\mathrm{F}$} & \multirow{7}{*}{51} & \multirow{7}{*}{22.7} & \multirow{7}{*}{7} & \multirow{7}{*}{$\begin{array}{l}\text { Left breast mixed invasive } \\
\text { ductal carcinoma, } \mathrm{s} / \mathrm{p} \text { modified } \\
\text { radical mastectomy, s/p } \\
\text { CCRT; L-spine spondylosis }\end{array}$} & Clonazepam 2 years & Estazolam 7 years \\
\hline & & & & & & Zolpidem 4 years & \\
\hline & & & & & & Estazolam 7 years & \\
\hline & & & & & & Lorazepam 6 months & \\
\hline & & & & & & Pregabalin 2 years & \\
\hline & & & & & & Imipramine 1 year & \\
\hline & & & & & & Amitriptyline 3 years & \\
\hline \multirow{7}{*}{11} & \multirow{7}{*}{$\mathrm{F}$} & \multirow{7}{*}{63} & \multirow{7}{*}{32.7} & \multirow{7}{*}{7} & \multirow{7}{*}{$\begin{array}{l}\text { Type } 2 \text { Diabetes Mellitus; } \\
\text { metabolic syndrome; stress } \\
\text { urinary incontinence; L4/5 } \\
\text { Spondylolisthesis }\end{array}$} & Glucophage 5 years & Copidogre 8 years \\
\hline & & & & & & Simvastatin 6 years & Insulin 2 years \\
\hline & & & & & & Flunarizine 4 months & Olmetec 4 years \\
\hline & & & & & & Glimepiride 4 years & Plaquenil 1 year \\
\hline & & & & & & Lorazepam 2 years; & Prednisolone 1 year \\
\hline & & & & & & Losartan 2 years & Simvastatin 6 years \\
\hline & & & & & & Copidogre 8 years & \\
\hline \multirow{6}{*}{12} & \multirow{6}{*}{$\mathrm{F}$} & \multirow{6}{*}{50} & \multirow{6}{*}{19.7} & \multirow{6}{*}{4} & \multirow{6}{*}{$\begin{array}{l}\text { Complex regional pain } \\
\text { syndrome }\end{array}$} & Pregabalin 1 years & Ultracet 3 years \\
\hline & & & & & & Celecoxib 1 years & \\
\hline & & & & & & Ultracet 3 years & \\
\hline & & & & & & Tramadol 7 months & \\
\hline & & & & & & Baclofen 1 months & \\
\hline & & & & & & Etoricoxib 7 months & \\
\hline \multirow{9}{*}{13} & \multirow{9}{*}{$\mathrm{F}$} & & & & & Meloxicam 6 months & Zolpidem 10 years \\
\hline & & & & & & Modipanol 4 years & Ultracet 5 years \\
\hline & & & & & & Zolpidem 10 years & Imigran 1 year \\
\hline & & & & & $\begin{array}{l}\text { Multiple sclerosis; Retractable } \\
\text { miaraine Psoriasis vulaaris. }\end{array}$ & Quetiapine 10 years & Quetiapine 10 years \\
\hline & & 50 & 20.7 & 15 & bilateral optic neuropathy; & Duloxetine 9 years & Morphin 6 years \\
\hline & & & & & deficiency anemia & Ultracet 5 years & Modipanol 4 years \\
\hline & & & & & & Topamax 8 months & Duloxetine 9 years \\
\hline & & & & & & Flunarizine 2 months & Amantadine 6 years \\
\hline & & & & & & Pregabalin 7 months & \\
\hline
\end{tabular}


Citation: Pin YW, Penn IW, Lin PH, Wang JC, Chuang E, et al. (2018) Effects of Intravenous Laser Irradiation of Blood on Pain, Function and Depression of Fibromyalgia Patients. Gen Med (Los Angeles) 6: 310. doi:10.4172/2327-5146.1000310

Page 5 of 8

\begin{tabular}{|c|c|c|c|c|c|c|c|}
\hline & & & & & & Morphine 6 years & \\
\hline & & & & & & Amantadine 6 years & \\
\hline \multirow{5}{*}{14} & \multirow{5}{*}{$\mathrm{F}$} & \multirow{5}{*}{68} & \multirow{5}{*}{28} & & \multirow{5}{*}{$\begin{array}{l}\text { Rheumatoid arthritis; T-L } \\
\text { spine degenerative joint } \\
\text { disease with spur formation; } \\
\text { hepatocellular carcinoma S3, } \\
\text { pT2Nx, Stage II, s/p } \\
\text { segmentectomy and } \\
\text { transcatheter arion arterial } \\
\text { chemoembolization }\end{array}$} & Lorazepam 2 years; & Alprazolam 5 years \\
\hline & & & & & & Alprazolam 5 years & Norvasc 4 years \\
\hline & & & & & & Prednisolone 2 months & Fludiazepam 1 year \\
\hline & & & & & & Sulfasalazine 2 months & Valsartan 3 years \\
\hline & & & & & & Etoricoxib 3 months; & \\
\hline \multirow{4}{*}{15} & \multirow{4}{*}{$\mathrm{F}$} & \multirow{4}{*}{45} & \multirow{4}{*}{17.9} & \multirow{4}{*}{11} & \multirow{4}{*}{$\begin{array}{l}\text { Sicca syndrome; peptic ulcer; } \\
\text { iron deficiency anemia; } \\
\text { Irritable bowel syndrome }\end{array}$} & Ultracet 8 years & Ultracet 8 years \\
\hline & & & & & & Amitriptyline 7 months & \\
\hline & & & & & & Pregabalin 3 months; & \\
\hline & & & & & & Clonazepam 2 years & \\
\hline
\end{tabular}

Table 1: Demographic and clinical characteristics of the study population.

Table 2 presented the measured outcomes before and after the treatment. The drugs therapy before admission achieved significance in VAS $(p=0.006)$ only. However, all tests including VAS $(p=0.001)$, numbers of tender points $(\mathrm{p}=0.002)$, FIQR $(\mathrm{p}=0.001)$, BDI $(\mathrm{p}=0.003)$ and PSQI $(\mathrm{p}=0.01)$ reached significance after the ILIB intervention. Moreover, comparing with drugs, the ILIB therapy demonstrated significantly positive effects on pain intensity, mood, sleep quality and QOL.

\begin{tabular}{|c|c|c|c|}
\hline Measurements & Medication + exercise (Pre/Post) & ILIB + exercise (Pre/Post) & Difference ( $p$-value) \\
\hline VAS & $8.00 \pm 1.4 / 6.93 \pm 1.8^{*}$ & $7.80 \pm 2.0 / 4.73 \pm 2.0^{* *}$ & 0.006 \\
\hline Tender point & $15.13 \pm 3.7 / 14.53 \pm 4.2$ & $14.00 \pm 4.0 / 10.73 \pm 5.7^{* *}$ & 0.038 \\
\hline FIQR & $75.86 \pm 20.5 / 69.17 \pm 22.0$ & $77.14 \pm 17.0 / 49.93 \pm 20.5^{\star *}$ & 0.005 \\
\hline BDI & $20.40 \pm 9.8 / 19.73 \pm 10.0$ & $19.93 \pm 9.7 / 10.46 \pm 7.1^{\star \star}$ & 0.016 \\
\hline PSQI & $15.60 \pm 3.5 / 15.26 \pm 4.1$ & $14.60 \pm 3.4 / 11.46 \pm 4.9^{*}$ & 0.027 \\
\hline
\end{tabular}

Table 2: Wilcoxon tests for pre and post-intervention comparisons and the differences between the two treatments.

Figures 1-5 portrayed the distributions of all measurements before and after medication and intravenous laser irradiation, which also highlighted the significant results in Wilcoxon tests.

Figure 1 displayed the Wilcoxon tests of VAS scores, which reached significance in both the intra-group comparisons and the differences between the two treatments.

Figure 2 demonstrate the number of tender points before and after medication and intravenous laser irradiation, and the Wilcoxon test achieved significance in laser group and the differences between the two treatments.

Figures 3-5 possessed similar Wilcoxon result as Figure 2, and they showed the distributions of the FIQR scores, the BDI scores, and the PSQI scores, separately. 


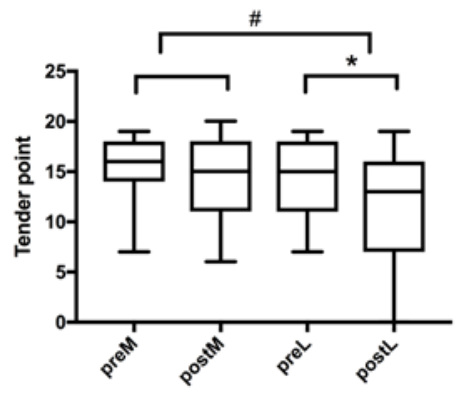

Figure 2: Number of tender points before and after medication and intravenous laser irradiation.

Abbreviation: M: Medication; L: Intravenous Laser Irradiation of Blood (ILIB)

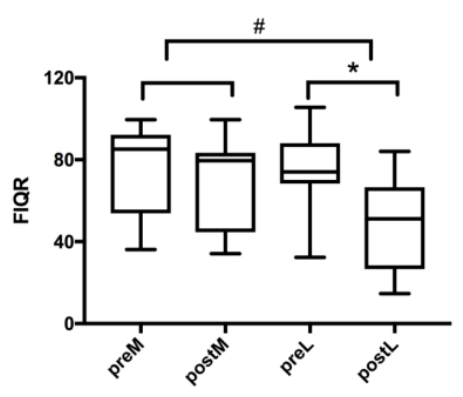

Figure 3: The distributions of FIQR scores before and after medication and intravenous laser irradiation.

Abbreviation: M: Medication; L: Intravenous Laser Irradiation of Blood (ILIB); FIQR: Revised Fibromyalgia Impact Questionnaire.

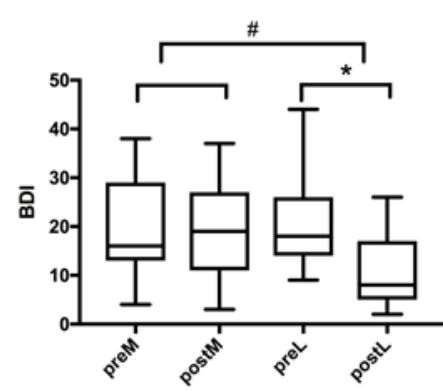

Figure 4: The distributions of BDI scores before and after medication and intravenous laser irradiation.

Abbreviation: M: Medication; L: Intravenous Laser Irradiation of Blood (ILIB); BDI: Revised Beck Depression Inventory.

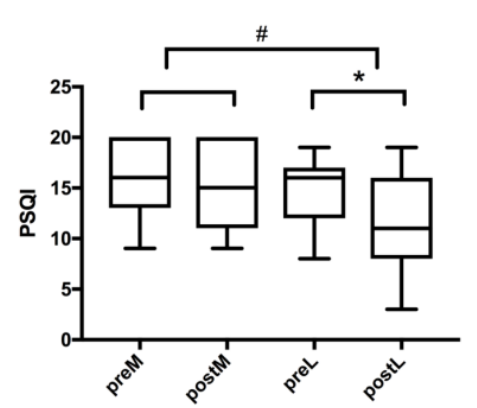

Figure 5: The distributions of PSQI scores before and after medication and intravenous laser irradiation.

Abbreviation: M: Medication; L: Intravenous Laser Irradiation of Blood (ILIB); PSQI: Pittsburgh Sleep Quality Index

\section{Discussion}

The etiology of fibromyalgia remains enigmatic and treatment results are often unsatisfactory. Currently, no cure for fibromyalgia exists. A multifaceted attempt tailored to the patients' needs is a crucial element in the treatment of pain, fatigue, and other diverse symptoms. Thus, ILIB has been widely used for its analgesic, spasmolytic, and sedative abilities $[12,16]$.

Our findings showed that the maximum pain intensity significantly decreased after the ILIB therapy. Previous meta-analyses have shown that red laser phototherapy effectively relieves pain through several etiologies, thereby making it a valuable tool for pain management $[27,28]$. In addition, the ILIB therapy had effects on peripheral neural stimulation, the regulation of microcirculation, and interrupting persistent pain, and it promotes analgesia $[12,29]$. The hallmark of ILIB therapy encompasses concepts of physical, biochemical mechanisms, tissue photobiology, vasodilation via increasing localized nitric oxide production, and cell signaling [12,29-34].

Non-restorative sleep, fatigue, and depression are common among patients with fibromyalgia, which is possibly due to the pathophysiology of central sensitization $[3,19,35,36]$. We observed that patients treated with ILIB had marked improvement in quality of life, sleep, and mood disorders, which was possibly mediated by soluble mediators such as endorphins and serotonin [31,37-39]. The increase in total body serotonin, including CNS serotonin after red light laser $[38,39]$, could have partially contributed to the improvement in pain, mood, and sleep improvements. In addition, research showed that mitochondrial impairment possibly has a significant effect causing the dysfunction of regulatory system cells, such as the nervous, endocrine, and lymphatic cells and their communicative network [40]. Hence, pain, mood disorders and sleep are prevalent in fibromyalgia. With ILIB, the redox system appears to be modulated resulting in ATP production and reduction in the generation of free radicals and super oxidants $[12,18]$ which could be related to the antioxidant defenses in patients with fibromyalgia. Delayed skeletal muscle fatigue and better exercise performance may also be associated with the recovery from oxidative stress [15,41].

Moreover, the majority of patients in our study used a wide range of medications (e.g. pregabalin, duloxetine, tricyclic antidepressants, and non-steroidal anti-inflammatory drugs) for pain relief, fatigue, and 
Citation: Pin YW, Penn IW, Lin PH, Wang JC, Chuang E, et al. (2018) Effects of Intravenous Laser Irradiation of Blood on Pain, Function and Depression of Fibromyalgia Patients. Gen Med (Los Angeles) 6: 310. doi:10.4172/2327-5146.1000310

Page 7 of 8

other symptoms. However, the relief felt from any single drug is minimal and most of the patients experienced side effects. By contrast, no complaints of discomfort were observed in all patients who had ILIB therapy.

Despite our efforts to reduce selection bias and to reduce confounding variables in our subjects by employing a vast collection of medical profiles, this study still has some limitations. No gold standard diagnostic biomarkers for fibromyalgia exist; thus, physicians only depend on patient-reported symptoms in understanding the complexities of this condition. Consequently, recall bias was not prevented in this study. Further studies may need prospective designs with randomized controls to limit recall bias.

\section{Conclusion}

This pilot study demonstrates that ILIB could lessen the effects of fibromyalgia, by improving pain severity, mood, sleep conditions, and quality of life. Hence, ILIB is a potential therapeutic regimen for patients with fibromyalgia.

\section{Conflict of Interest}

All authors declare that there is no conflict of interest.

\section{Acknowledgment}

The authors thank the editor and series editor for constructive criticisms of an earlier version of this manuscript.

\section{References}

1. Kashikar ZS, Graham TB, Huenefeld MD, Powers SW (2000) A review of biobehavioral research in juvenile primary fibromyalgia syndrome. Arthritis Care Res 13: 388-397.

2. Theoharides TC, Tsilioni I, Arbetman L, Panagiotidou S (2015) Fibromyalgia syndrome in need of effective treatments. J Pharmacol Exp Ther 355: 255-263.

3. Chinn S, Caldwell W, Gritsenko K (2016) Fibromyalgia pathogenesis and treatment options update. Curr Pain Headache 20: 25.

4. Staud R (2006) Biology and therapy of fibromyalgia: Pain in fibromyalgia syndrome. Arthritis Res Ther 8: 208.

5. Woolf CJ (2011) Central sensitization: Implications for the diagnosis and treatment of pain. Pain 152: 2-15.

6. Littlejohn G (2015) neurogenic neuro inflammation in fibromyalgia and complex regional pain syndrome. Nat Rev Rheumatol 11: 639.

7. Schmidt WT, Diers M (2017) new insights into the pathophysiology and treatment of fibromyalgia. Biomed 5:22.

8. Herpich CM, Leal-Junior EC, Amaral AP, de Paiva Tosato J, dos Santos Glória IP, et al. (2014) Effects of phototherapy on muscle activity and pain in individuals with temporomandibular disorder: A study protocol for a randomized controlled trial. Trials 15: 491.

9. Da Silva MM, Albertini R, Leal-Junior EC, De Carvalho PD, Silva JA, et al. (2015) Effects of exercise training and photobiomodulation therapy (EXTRAPHOTO) on pain in women with fibromyalgia and temporomandibular disorder: Study protocol for a randomized controlled trial. Trials 16: 252.

10. Gür A, Karakoc M, Nas K, Cevik R, Sarac J, et al. (2002) Efficacy of low power laser therapy in fibromyalgia: A single-blind, placebo-controlled trial. Lasers Med Sci 17: 57-61.

11. Ruaro JA, Fréz AR, Ruaro MB, Nicolau RA (2014) Low-level laser therapy to treat fibromyalgia. Lasers in medical science 29: 1815-1859.
12. Momenzadeh S, Abbasi M, Ebadifar A, Aryani M, Bayrami J, et al. (2015) The intravenous laser blood irradiation in chronic pain and fibromyalgia. Journal of lasers in medical sciences 6: 6 .

13. Dube A, Bansal H, Gupta PK (2003) Modulation of macrophage structure and function by low level He-Ne laser irradiation. Photochem Photobiol Sci 2: 851-855.

14. Funk JO, Kruse A, Kirchner H (1992) Cytokine production after helium neon laser irradiation in cultures of human peripheral blood mononuclear cells. J Photochem Photobiol B 16: 347-355.

15. De Marchi T, Junior EC, Bortoli C, Tomazoni SS, Lopes-Martins RÁ, et al. (2012) Low-level laser therapy (LLLT) in human progressive-intensity running: Effects on exercise performance, skeletal muscle status, and oxidative stress. Lasers Med Sci 27: 231-236.

16. Momenzadeh S, Akhyani V, Razaghi Z, Ebadifar A, Abbasi M, et al. (2016) Evaluation of the effects of intravenous and percutaneous low level laser therapy in the management of shoulder myofascial pain syndrome. J Lasers Med Sci 7: 16.

17. Torsten E, Wieden MD (2008) Fibromyalgia in pain therapy: Mechanisms and treatment options in laser therapy. Schmerz \& Akupunktur 34: 130-136.

18. Huang SF, Tsai YA, Wu SB, Wei YH, Tsai PY, et al. (2012) Effects of intravascular laser irradiation of blood in mitochondria dysfunction and oxidative stress in adults with chronic spinal cord injury. Photomed Laser Surg 30: 579-586.

19. Fitzcharles MA, Ste-Marie PA, Goldenberg DL, Pereira JX, Abbey S, et al. (2012) Canadian guidelines for the diagnosis and management of fibromyalgia syndrome: Executive summary. Pain Res Manag 18:119-126.

20. Ablin J, Fitzcharles MA, Buskila D, Shir Y, Sommer C, et al. (2013) Treatment of fibromyalgia syndrome: Recommendations of recent evidence-based interdisciplinary guidelines with special emphasis on complementary and alternative therapies. Evid Based Complement Alternat Med 2013.

21. Wolfe F, Clauw DJ, Fitzcharles MA, Goldenberg DL, Katz RS, et al. (2010) The american college of rheumatology preliminary diagnostic criteria for fibromyalgia and measurement of symptom severity. Arthritis Care Res 62: 600-610.

22. Wolfe F, Clauw DJ, Fitzcharles MA, Goldenberg DL, Häuser W, et al. (2011) Fibromyalgia criteria and severity scales for clinical and epidemiological studies: A modification of the ACR preliminary diagnostic criteria for fibromyalgia. J Rheumatol 38: 1113-1122.

23. http://www.nj.gov/health/ceohs/documents/phss/ fda_photosensitivitylist.pdf

24. Kühner C, Bürger C, Keller F, Hautzinger M (2007) Reliability and validity of the revised beck depression inventory (BDI-II). results from german samples. NERVENARZT 78: 651-656.

25. Buysse DJ, Reynolds CF, Monk TH, Berman SR, Kupfer DJ, et al. (1989) The pittsburgh sleep quality index: A new instrument for psychiatric practice and research. Psychiatry Res 28: 193-213.

26. Bennett RM, Friend R, Jones KD, Ward R, Han BK, et al. (2009) The revised fibromyalgia impact questionnaire (FIQR): Validation and psychometric properties. Arthritis Res Ther 11: R120.

27. Fulop AM, Dhimmer S, Deluca JR, Johanson DD, Lenz RV, et al. (2010) A meta-analysis of the efficacy of laser phototherapy on pain relief. The Clinical journal of pain 26: 729-736.

28. Jang H, Lee H (2012) Meta-analysis of pain relief effects by laser irradiation on joint areas. Photomed Laser Surg 30: 405-417.

29. Brill GE, Grigoriev SN, Romanova TP (1993) Changes of leucocyte metabolism in HeNe laser blood irradiation in vitro. in optical methods of biomedical diagnostics and therapy 1981: 204-210.

30. Boev SS, Selivonenko VG (1997) The impact of the intravenous He-Ne laser therapy on the antioxidant system in patient with stable exertion angina and postinfarct cardiosclerosis. Klinicheskaia meditsina.75: 30-33.

31. Weber MH, Fuganger May T, Wolf $\mathrm{T}$ (2007) The intravenous laser blood irradiation - introduction of a new therapy. J Lasers Med Sci 50: 12-23. 
Citation: Pin YW, Penn IW, Lin PH, Wang JC, Chuang E, et al. (2018) Effects of Intravenous Laser Irradiation of Blood on Pain, Function and Depression of Fibromyalgia Patients. Gen Med (Los Angeles) 6: 312. doi:10.4172/2327-5146.1000312

Page 8 of 8

32. Karu TI, Pyatibrat LV, Kolyakov SF, Afanasyeva NI (2008) Absorption measurements of cell monolayers relevant to mechanisms of laser phototherapy: Reduction or oxidation of cytochrome $c$ oxidase under laser radiation at 632.8 $\mathrm{nm}$. Photomed Laser Surg 26: 593-599.

33. Mitchell UH, Mack GL (2013) Low-level laser treatment with nearinfrared light increases venous nitric oxide levels acutely: A single-blind randomized clinical trial of efficacy. Am J Phys Med Rehabil 92: 151-156.

34. Samoilova KA, Zhevago NA, Petrishchev NN, Zimin AA (2008) Role of nitric oxide in the visible light-induced rapid increase of human skin microcirculation at the local and systemic levels: II. healthy volunteers. Photomed Laser Surg 26: 443-449.

35. Cassisi G, Sarzi PP, Alciati A, Casale R, Bazzichi L, et al. (2008) Symptoms and signs in fibromyalgia syndrome. Reumatismo 60:15-24.

36. Schmidt Wilcke T, Clauw DJ (2011) Fibromyalgia: From pathophysiology to therapy. Nat Rev Rheumatol 7: 518.

37. Bjordal JM, Johnson MI, Iversen V, Aimbire F, Lopes-Martins RA, et al. (2006) Low-level laser therapy in acute pain: A systematic review of possible mechanisms of action and clinical effects in randomized placebo-controlled trials. Photomed Laser Ther 24: 158-168.

38. Tomaz de MM, Núñez SC, Kato IT, Ribeiro MS (2016) Light therapy modulates serotonin levels and blood flow in women with headache: A preliminary study. Exp Biol Med 241: 40-45.

39. Walker J (1983) Relief from chronic pain by low power laser irradiation. Neurosci Lett 43: 339-344.

40. Cordero MD, Alcocer Gómez E, Cano García FJ, De Miguel M, Carrión AM, et al. (2011) Clinical symptoms in fibromyalgia is better associated to lipid peroxidation levels in blood mononuclear cells rather than in plasma. PLoS ONE 6: e26915.

41. Borsa PA, Larkin KA, True JM (2013) Does phototherapy enhance skeletal muscle contractile function and postexercise recovery? A systematic review. J Athl Train 48: 57-67. 